\title{
One patient - different features of thrombus
}

\author{
Kristina Marić Bešić, Maja Strozzi, Zoran Miovski* \\ University Hospital Centre Zagreb, Zagreb, Croatia
}

\begin{abstract}
Introduction: STEMI patients with a large thrombus burden are at high risk of adverse clinical outcomes. Distal embolization, leading to impaired microvascular perfusion and noreflow phenomen but also stent thrombosis are frequent complications.
\end{abstract}

Case report: A 57-year-old woman was admitted to our department because of inferoposterior STEMI. Coronary angiography revealed a large thrombus in the RCA ostium. After guiding catheter placement distal embolization occurred and this resulted with RPL occlusion. Direct stenting of ostial RCA with one BMS was performed. Although thrombus aspiration and balloon angioplasty of RPL were performed, noreflow occurred. The patient received intracoronary bolus of eptifibatide and during the next 18 hours eptifibatide infusion was continued. She was relived of chest pain and the ECG was normalized. After three days the patient once again had chest pain with inferoposterior STEMI. Coronary angiography showed a large thrombus in the implanted BMS with reduced TIMI flow but patent RPL. Because no thrombectomy catheter was available, only PTCA was done. A good angiographic result was achieved, but once again distal embolization and occlusion of RPL occurred. Eptifibatide infusion was continued during the next 30 hours and ST-segment resolution was obtained.
Discussion: Patients with distal embolization and no-reflow have significantly higher rates of acute or subacute stent thrombosis. If mechanical thrombectomy is not available or fails, glycoprotein IIb/IIla inhibitors are used with various efficacies. In our patient eptifibatide was useful in obtaining flow in the RPL, but nevertheless subacute stent thrombosis occurred. Therefore, more successful treatment options in these patients are needed.

Conclusion: The presence of large coronary thrombus at the time of primary $\mathrm{PCl}$ still remains a challenge for the interventional cardiologist. It is associated with a greater frequency MACE and is a strong independent predictor of late mortality.

KEYWORDS: large thrombus, no-reflow, stent thrombosis.

\section{Received: $5^{\text {th }}$ Mar 2013}

*Address for correspondence: Klinički bolnički centar Zagreb, Kišpatićeva 12, HR10000 Zagreb, Croatia.

Phone: +385-1-2388-888

E-mail: kikadzu@yahoo.com

\section{Literature}

1. Sianos G, Papafaklis MI, Daemen J, et al. Angiographic stent thrombosis after routine use of drug-eluting stents in ST-segment elevation myocardial infarction: the importance of thrombus burden. J Am Coll Cardiol. 2007; 50(7):573-83.

2. Sianos G, Papafaklis MI, Serruxy PW. Angiographic thrombus burden classification in patients with ST-segment elevation myocardial infarction treated with percutaneous coronary intervention. J Invasive Cardiol. 2010;22(10 Suppl B):6B-14B.

3. Dangas GD, Caixeta A, Mehran R, et al. Frequency and predictors of stent thrombosis after percutaneous coronary intervention in acute myocardial infarction. Circulation. 2011;123: 1745-56. 